\title{
Abnormalities of airway epithelial function and the implications of the discovery of the cystic fibrosis gene
}

\author{
Alan W Cuthbert
}

Of all the functional abnormalities present in cystic fibrosis, those affecting the lung are the most serious. In 1989 research workers in Canada and the United States reported the structure of the gene responsible for $70 \%$ of cystic fibrosis among white people. ${ }^{1-3}$ I shall explore what is known about abnormal lung function in cystic fibrosis at the cellular and molecular level and discuss how the recently discovered genetic information may be related to the cellular defects. Although it is too early to speak of a treatment for cystic fibrosis, the increased understanding of underlying mechanisms suggests ways in which treatment may be approached in the future.

By means of a painstaking combination of chromosome walking and jumping and complementary DNA (cDNA) hybridisation over half a million base pairs on the long arm of chromosome 7 band $q 31$ have been sequenced..$^{1-3}$ The putative protein coded for by the cDNA for the cystic fibrosis locus consists of 1480 amino acids. The trinucleotide codon for the 508th amino acid from the $N$ terminus (phenylalanine) was found to be deleted in $70 \%$ of patients with cystic fibrosis. On the basis of analogy and homology a tentative structure for the protein coded for by the gene has been deduced (figure 1). The protein has been named the cystic fibrosis transmembrane regulator.

This protein has two related motifs, each consisting of six membrane spanning regions joined by a long polypeptide chain. It is proposed that very little $(5 \%)$ of the protein is exposed externally and that some $80 \%$ is in the cytosol. Two features of the cytosolic domain are important. The first is a highly charged $R$ domain with 16 potential sites for phosphorylation and the second two nucleotide binding folds, which may bind or even hydrolyse ATP. The phenylalanine deletion $(\Delta \mathrm{F} 508)$ occurs in the first nucleotide binding fold.

Other proteins with similar structures and a fair degree of homology are already known, principally the $\mathbf{P}$ glycoproteins or multiple drug resistance (MDR) proteins. These proteins are responsible for the energy dependent efflux of cytotoxic drugs from cells. Increased expression of multiple drug resistance proteins after exposure to cytotoxic

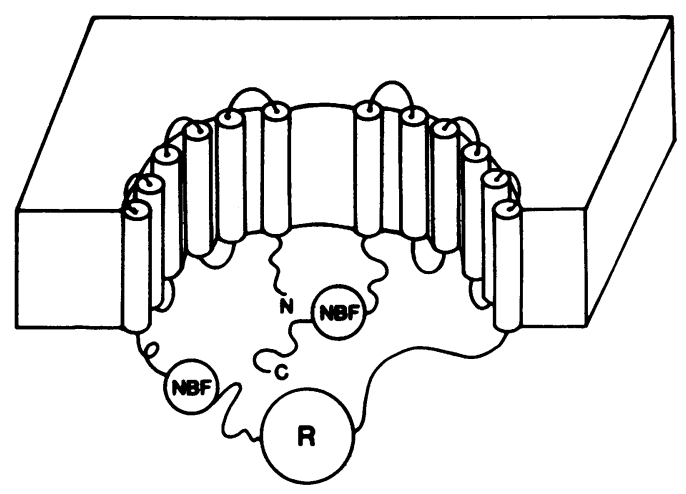

Figure 1 Hypothetical structure of the cystic fibrosis transmembrane regulator. Two sets of six membrane spanning domains are joined by a long polypeptide chain. Two nucleotide binding folds (NBF) bind ATP. In cystic fibrosis the missing phenylalanine is in the nucleotide binding fold nearest to the $N$ terminus. The $R$ domain contains 16 potential phosphorylation sites. Note that very little of the protein is exposed to the external (upper) surface of the cell.

drugs may be a major cause of drug resistance in cancer chemotherapy. ${ }^{4}$

\section{Transepithelial ion transport in the} respiratory system

What goes awry in the respiratory system in cystic fibrosis and how is this related to the presence of the cystic fibrosis transmembrane regulator protein with phenylalanine deleted at position 508? It is obvious, but worth restating, that biological systems have no way of pumping water. Water can be made to move across biological barriers only by osmosis-provided, of course, that the barriers are water permeable. Movement of fluid therefore depends on solute transport, usually of inorganic ions. In the lungs surface liquid elaborated in the alveoli and small airways is moved by ciliary action to more proximal regions. As fluid does not accumulate in the proximal regions even though there is a 4000 fold reduction in total volume and a comparable reduction in surface area, fluid must be reabsorbed as a consequence of ion transport. ${ }^{5}$ These same processes are vitally important at birth for converting fluid filled lungs to respiratory organs.

How do cells lining the respiratory system, 

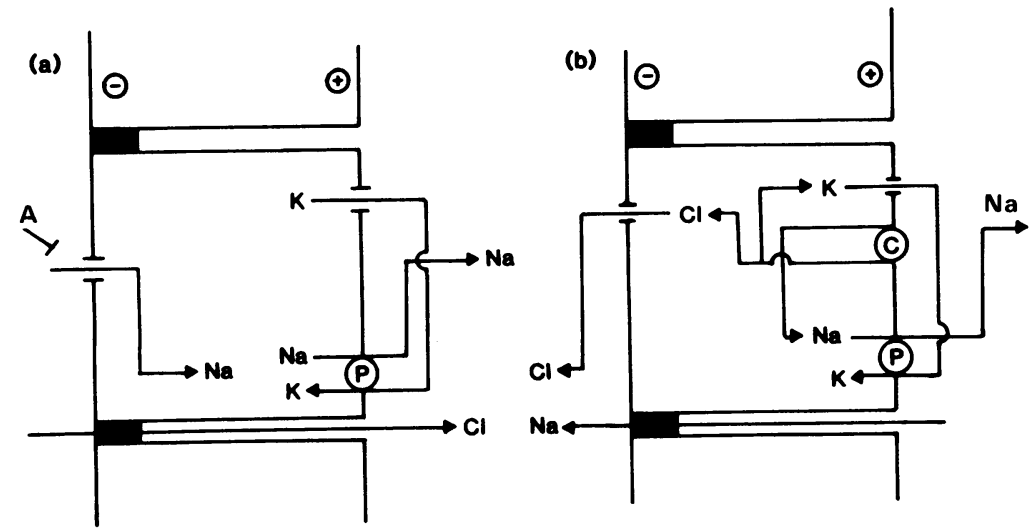

Figure 2 Models of electrogenic sodium absorption (a) and electrogenic chloride secretion (b). Cells are joined at the apical surface by tight junctions. In (a) sodium ions enter the cell through apical sodium channels and are pumped out of the basolateral surface by the sodium pump (P). Potassium ions cycle via the sodium pump and basolateral $K$ channels. In (b) chloride ions enter the cell by a basolaterally located carrier $(C)$ along with potassium and sodium ions. The latter two are dealt with by the pump and potassium channels as before. Chloride ions leave through the apical surface via chloride channels sensitive to cyclic AMP. Counterions, chloride in (a) and sodium in (b), move through paracellular pathways. A-amiloride.

particularly in the more proximal regions, effect fluid absorption? Two types of transporting mechanism are depicted in figure 2namely, electrogenic sodium absorption and electrogenic chloride secretion. Both processes are powered by the sodium pump, a sodium-potassium activated, magnesium dependent ATPase. The transporting epithelial cells are asymmetrical-that is, the apical and basolateral membrane domains differ in their properties in such a way that the molecular apparatus of transport, ion channels, ion pumps, and exchange mechanisms are exclusively assigned to one membrane domain or the other. These molecular entities are prevented from passing from one domain to the other by the tight junctions between individual cells. How an individual cell is able to insert these protein molecules into the correct membrane domain remains an intriguing and largely unsolved problem.

Sodium absorption is dependent on the presence of selective sodium channels in the apical membrane (fig 2a), which can be specifically blocked by drugs such as amiloride and triamterene. ${ }^{6}$ Although sodium channels are present there will be net sodium influx into the cell only if a favourable electrochemical gradient exists. Sodium ions are expelled from the cell across the basolateral membrane via the sodium pump, which has the stoichiometry of $3 \mathrm{Na}^{+}$to $2 \mathrm{~K}^{+}$ions. The transfer of the sodium cation across the epithelial barrier creates a favourable electrical gradient for the movement of the chloride counteranion, which moves passively across the tissue, probably by a paracellular route. Potassium ions establish electrochemical equilibrium across the basolateral face via potassium channels, which in many systems are sensitive to the concentration of intracellular calcium. Electrogenic sodium absorption can be prevented by inhibitors of the sodium pump, such as ouabain and other cardiac glycosides. There appear to be few endogenous substances that can regulate this sodium absorptive process in respiratory epithelium, though adrenaline is known to stimulate the process in the perinatal period. ${ }^{7}$

Normally electrogenic chloride secretion is not present in respiratory epithelium, but it can be activated by beta agonists and other agents that increase intracellular cyclic AMP, prostaglandins, and bradykinin. The first step in chloride secretion requires that chloride is accumulated in the cell to a level greater than expected from the elctrochemical gradient. The cell does this by using a sodium-potassium chloride cotransporter with the stoichiometry $\mathrm{Na}^{+}: \mathrm{K}^{+}: \mathrm{Cl}^{-}$1:1:2 (fig 2b). The energy stored in the electrochemical gradient for sodium between the outside of the cell and the interior provides the energy source for driving potassium and chloride uphill into the cell. The sodium and potassium ions that enter the cell along with chloride are dealt with by the sodium pump and by equilibration through basolateral $\mathrm{K}^{+}$channels respectively. Chloride is then free to move out of the cell, across the apical membrane, and down its electrochemical gradient, provided that the chloride channels are open. Agents that increase cyclic AMP increase the open state probability of these channels. Thus the processes of chloride secretion lead to a transfer of charge (anions) across the tissue such that a favourable gradient for accompanying countercation movement is generated. The main counterions will be sodium ions moving mainly through paracellular routes.

Both the absorptive and secretory processes that have been described will influence water movement, inwards and outwards respectively, across the epithelium. This is possible because respiratory epithelium is water permeable. This is not so for epithelia with low water permeability (for example, sweat duct), where salts can be absorbed without consequent fluid movement. The presence in the pulmonary system of these transport processes, with a predominant, unregulated absorptive process plus a secretory process that can be activated and regulated by autacoids and transmitters, provides the opportunity for fine tuning of the thickness of the fluid (sol) phase lining the proximal airways. The control of the thickness of the fluid lining has not been definitely demonstrated, but it is known that both these processes are present in epithelium lining the proximal airways and, more importantly, how they are modified in cystic fibrosis.

\section{Abnormalities of epithelial ion transport in cystic fibrosis}

The first insightful observation in relation to the transport function in cystic fibrosis airway epithelium was that the potential difference across the nasal mucosa and bronchi of patients with cystic fibrosis was around twice that of subjects not suffering from cystic fibrosis. ${ }^{8}$ On its own this result is difficult to interpret because either increased sodium absorption or reduced chloride conductance at the apical surface would give this result.

When amiloride is superfused into the apical surface of nasal epithelia in vivo the potential 

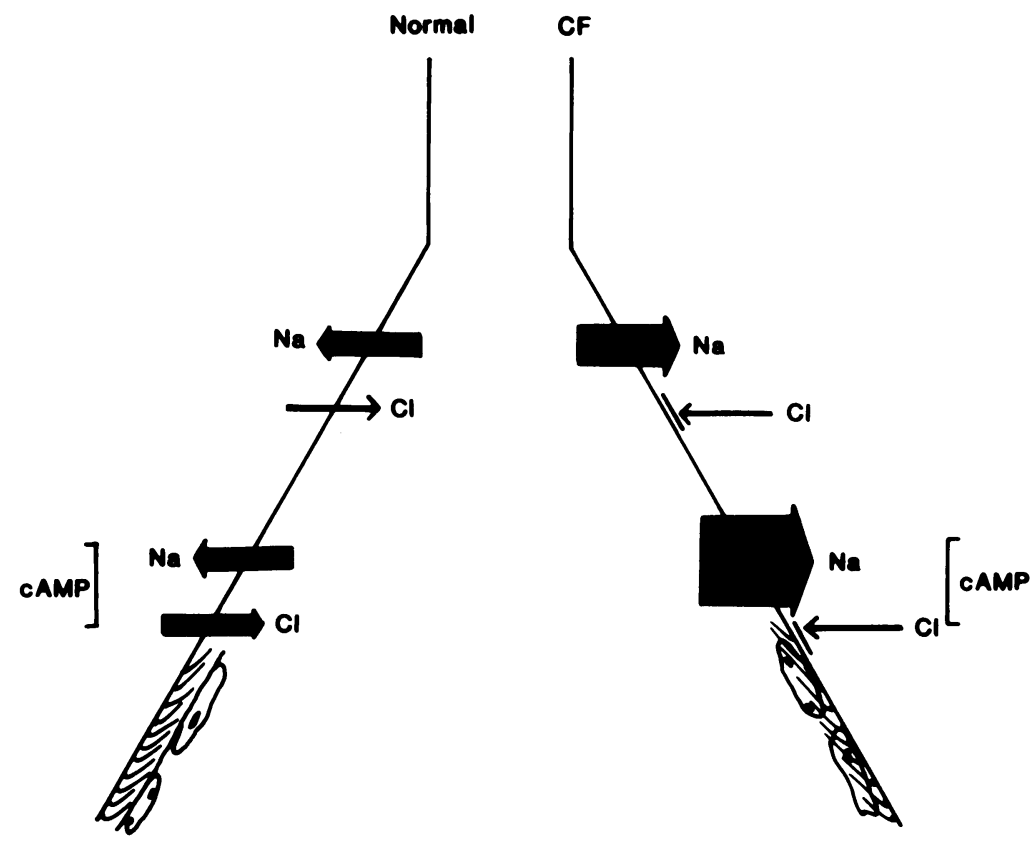

Figure 3 Summary of the differences between airway epithelium in normal and cystic fibrosis tissues. In cystic fibrosis sodium absorption ( $\mathrm{Na}$ ) is exaggerated and chloride secretion $(\mathrm{Cl})$ is blocked, even in the presence of secretagogues that increase cyclic $A M P$ $(c A M P)$. In normal epithelium secretagogues increase chloride secretion whereas in cystic fibrosis sodium absorption is enhanced. Excessive dehydration may remove the sol phase, depositing mucus flakes with adherent bacteria on to the cilia.

difference falls. Both the absolute fall and the percentage inhibition of the nasal potential difference was greater in patients with cystic fibrosis than in normal controls ${ }^{9}$ and this effect could be mimicked by superfusing sodium free solutions. In contrast, superfusion with chloride free solutions increased the luminal negativity, but considerably more in normal subjects than in patients with cystic fibrosis. ${ }^{9}$ These additional findings support the notion that both increased sodium transport and reduced apical chloride conductance are responsible for the potential difference in the airway epithelium in cystic fibrosis. Monolayers of cultured nasal epithelial cells from controls and patients with cystic fibrosis showed similar potential changes when subjected to amiloride or to low sodium or low chloride conditions. ${ }^{10}$ This means that cells retain their cystic fibrosis characteristics through many generations of cell division in culture, exactly what is expected if abnormal characteristics are tied to a genetic defect.

Since these early, largely in vivo experiments, various lines of evidence have confirmed that in airway epithelium from patients with cystic fibrosis sodium absorption is enhanced and apical chloride permeability is low or absent, the latter preventing chloride secretion in response to secretagogues that raise intracellular cAMP. The detailed evidence for this cannot be given here, but the central findings are summarised below with key references.

1 Isolated epithelial sheets from resected nasal turbinate material or nasal polyps were used to measure active sodium absorption. The rate of sodium transport in cystic fibrosis tissue was about twice that in control tissue. ${ }^{11-13}$

2 In cultured airway epithelial cells apical chloride permeability was lower in cystic fibrosis cells than in non-cystic fibrosis cells. ${ }^{14} 15$ 3 By application of various agents that activate adenylate cyclase (beta agonists, forskolin) to monolayer cultures of airway epithelial cells chloride secretion was stimulated in normal but not cystic fibrosis cells. In cystic fibrosis monolayers beta agonists further enhanced sodium absorptive processes. These differences could not be explained by differences in the generation of cAMP or in the amount of cAMP dependent protein kinases in the tissue. ${ }^{16-18}$

4 Bradykinin and A23187, both of which increase intracellular calcium concentration $\left(\mathrm{Ca}_{\mathrm{i}}\right)$, are able to elicit transient chloride secretory responses in cystic fibrosis epithelia. ${ }^{19}$ It is, however, possible that raised $\mathrm{Ca}_{\mathrm{i}}$ activates basolateral $\mathrm{K}^{+}$channels, leading to hyperpolarisation of the apical membrane, thus increasing the electrochemical potential for efflux, even though the membrane has a low chloride conductance. Figure 3 provides a summary of the comparisons in transporting properties between cystic fibrosis and normal respiratory epithelium, plus the effects of different types of secretagogues.

\section{Possible consequences of transporting abnormalities in cystic fibrosis}

Mucociliary clearance depends on the functioning of cilia within the sol phase lining the respiratory passages. Not only is fluid moved toward the proximal airways but mucus and entrapped foreign particles are moved to a position from which they can be eliminated from the lung. Excessive solute transport out of the airways, with consequent fluid absorption, may reduced the sol phase, depositing thick, viscid mucus on the cilia. Mucus deposits are difficult to dislodge and provide a breeding ground for Staphylococus aureus and Pseudomonas aeruginosa. Although this is a reasonable hypothesis there is little definitive evidence to support it. The reason is a technical one-it is difficult to sample fluid from the airways without evaporative losses, making accurate determination of composition very difficult.

The chemical composition of secreted mucus is known to be altered in cystic fibrosis, with increased sulphation of high molecular weight glycoconjugates. ${ }^{20}$ As cystic fibrosis is a single gene defect it becomes increasingly difficult to explain how properties as diverse as mucus composition and chloride conductance are related to a single abnormal form of the cystic fibrosis transmembrane regulator, though abnormal chloride transport may increase the concentration of intracellular sulphate and increase substrate driven sulphation of glycoproteins.

\section{Molecular correlates of abnormal transporting properties}

Patch clamping is a relatively new technique that allows the functional activity of single ion channels to be examined. Theoretically the concept is straightforward. First devise a way 
of isolating a single ion channel so that its activity can be monitored, without interference from the thousands of other ion channels present in a cell membrane. Secondly, find a way of detecting whether the channel is open or closed. This is done by monitoring the flow of ions through the channel with sensitive current amplifiers. Ion channels allow millions of ions to pass each second, giving rise to currents in the picoampere $\left(10^{-12} \mathrm{~A}\right)$ range. By measuring the relation between the current and the voltage across the channel and taking account of the ion concentration either side of the membrane you can assess channel selectivity. An all important factor is the reversal potential (the potential at which the current through the channel reverses its direction); application of the GoldmanHodgkin-Katz equation and comparision of actual and theoretical values allow the channel to be designated as selective for chloride, sodium, potassium, or calcium. To isolate a single ion channel a fire polished glass electrode with a tip diameter of a few microns is gently pushed against the surface of a cell. A self sealing process occurs such that the resistance between the conducting fluid in the electrode and the bathing fluid outside is very large (gigaohm seal). The patch so isolated will contain a few ion channels, or preferably a single one. Recordings are made of the currents flowing across the patch either in the cell attached mode or by pulling the patch off the cell.

Figure 4 shows a patch clamp record from a chloride ion channel from a human cystic fibrosis sweat gland cell. Diagrammatic representation of major findings in cystic fibrosis and airway epithelial cells is given in figure 5, which shows idealised diagrams of patch clamp recordings. Figures $5 a$ and $5 b$ shows the usual features seen with patch clamping. The current flowing through a particular type of ion channel is constant at a given voltage-that is, the channel conductance is characteristic of the channel, and channels are either open or closed. If two channels are present in a patch and are open simultaneously then the current flowing is twice that of a single channel. By contrast, the duration of the open and closed periods varies even for a single channel. In the simplest systems analysis of patch clamp records shows that open and closed time histograms are fitted by single exponentials, suggesting that a single process is responsible for transitions from open to closed.

Two groups have reported their findings on chloride channels in airway epithelial cells using the patch clamp technique. ${ }^{21}{ }^{22}$ In the cell attached configuration chloride channels were rarely seen unless the cell was activated by agents that increased cAMP. After stimulation there was an increased probability of chloride channel opening in normal cells (fig $5 c$ ) but not in cystic fibrosis cells (fig $5 d$ ). Again with the cell attached configuration, the calcium ionophore A23187 was able to activate chloride channels in both normal and cystic fibrosis cells. Isolated patches from cells activated by cAMP generating secretagogues showed chloride channel activity (fig $5 e i$ ), whereas patches from similarly

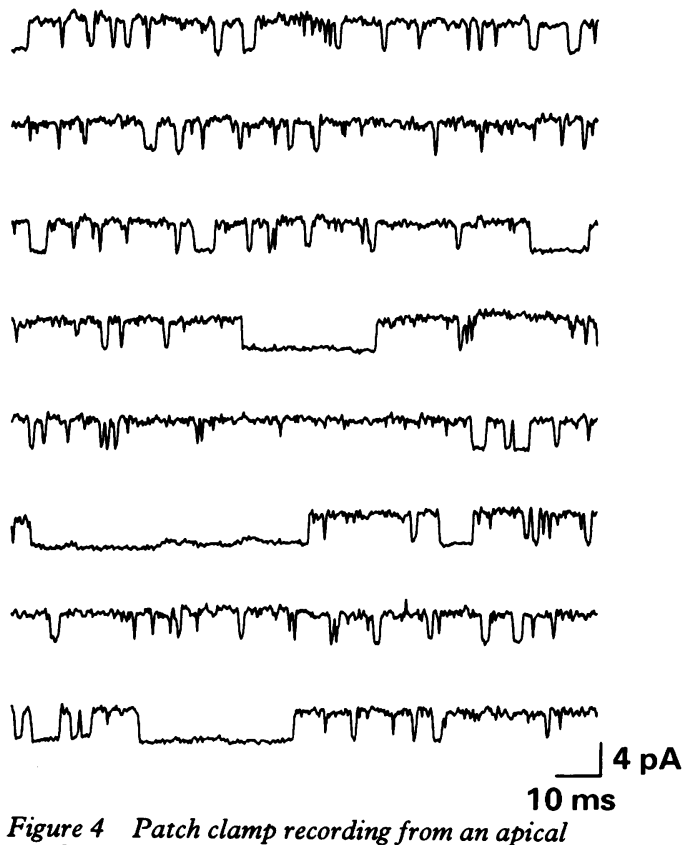

membrane patch showing the activity of a single chloride selective channel from a cystic fibrosis sweat gland cell. Channel opening is in the upward direction, indicating chloride ion flow from outside the apical surface to inside. The solution bathing both sides of the patch contained potassium (140 mmol/l), sodium ( $7 \mathrm{mmol} / \mathrm{l})$. The holding potential was $70 \mathrm{mv}$ with the outside apical surface negative.

treated cystic fibrosis cells were electrically silent (fig $5 e$ ii). Chloride channels could be activated in cystic fibrosis patches either by strong depolarisation or by exposure of the cytosolic face to calcium ions (fig $5 e$ iii). The effects of these last two manoeuvres are not

(a)

(b)
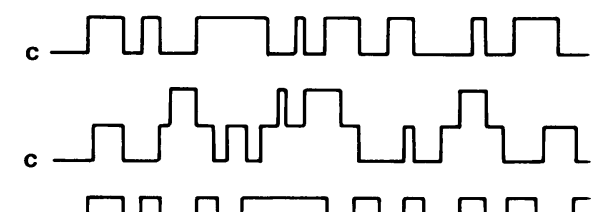

(c)

(d)

(ei)

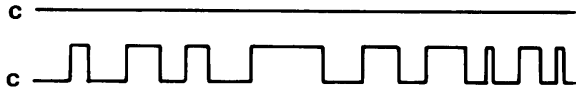

(eii)

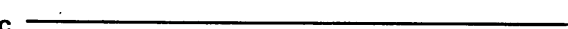

(eiii)

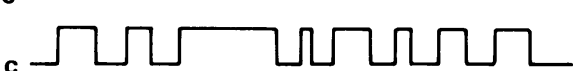

(fi)

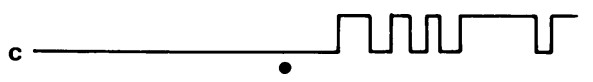

(fii) $\mathbf{c} \longrightarrow$

Figure 5 Theoretical patch clamp records from chloride channels. $c$ indicates the current level at which the channel is closed. The patch may contain one (a) or more than one (b) channel. Activation of a respiratory epithelial cell with cyclic AMP (cAMP) increases the probability that the chloride channels are open. In normal cells channel activation can be seen in the cell attached configuration (c) but not with cystic fibrosis cells $(d)$. When the patch is pulled from activated cells channel activity continues in patches from normal cells (ei) but is still absent in patches from cystic fibrosis cells (eii). Patches from cystic fibrosis cells can, however, be activated by strong depolarisation (eiii). When a patch is held at a potential that prevents chloride channel activation opening can be induced by a cocktail of ATP, $c A M P$, and the catalytic subunit of protein kinase $A$ (added at - ) in patches from normal $(f i)$ but not cystic fibrosis cells (fii). 
immediate or necessarily reversible and it is not clear how activation is achieved. Kunzelmann et $a l^{23}$ have shown that if isolated patches are formed at $37^{\circ} \mathrm{C}$ rather than at room temperature there is immediate activation of chloride channels in cystic fibrosis cells without the need to apply strong depolarisation. He has argued that regulation of the chloride channel is defective rather than the channel itself. Possibly the cytosol in cystic fibrosis contains a tonic inhibitor of the chloride channel that is removed once an inside out patch is formed. Finally, as shown in figure $5 f$, when apical membrane patches are held at room temperature and at a voltage inhibiting channel activation, addition of ATP and the catalytic subunit of protein kinase A causes channel activation in normal but not cystic fibrosis membranes. Thus there appears to be a phosphorylation defect at a stage later than either cAMP generation or the activation of protein kinase A. ${ }^{24}$ There are two other findings with a bearing on this problem. Firstly, the patch clamp findings have now been confirmed in an immortalised, virally transformed epithelial line developed from cystic fibrosis airway cells. This establishes that the distinctive cystic fibrosis phenotype is preserved in cells after many generations of culture in vitro, ${ }^{26}$ and therefore cannot be related to the infected conditions in cystic fibrosis airways. Secondly, apical membrane chloride channels incorporated into lipid bilayers show properties similar to those in normal membranes, but undergo a rapid run down. Activity can be restored by addition of the phosphorylating "cocktail" including the catalytic subunit of protein kinase $\mathrm{A}$, indicating that a phosphorylation event is concerned in the functioning of airway chloride channels. ${ }^{27}$ Protein kinase $\mathrm{C}$ can also activate chloride channels in airway epithelial cells, but again regulation by this kinase is defective in cystic fibrosis. ${ }^{28}$ Whatever method has been used to activate cystic fibrosis chloride channels in vitro their properties have proved to be identical to those of normal channels-that is, conductance of around $50 \mathrm{pS}$ at $0 \mathrm{mv}$, an outwardly rectifying current-voltage relationship, and a $\mathrm{Cl}^{-}$to $\mathrm{Na}^{+}$ selectivity ratio of 10:1.

Far less is known about sodium channel mechanisms in airway cells. The mean channel lifetime for sodium channels in cystic fibrosis cells is twice that of normal channels, providing a correlate for the increased sodium reabsorption in cystic fibrosis. ${ }^{29}$ It has also been shown that the macroscopic $\mathrm{Kd}$ for amiloride is increased and there is an altered relation between sodium concentration and sodium transport in cystic fibrosis epithelium. ${ }^{30}$ These latter studies were made with sweat duct epithelium, however, not airway epithelium. Nevertheless, a picture is emerging of altered molecular characteristics affecting both chloride and sodium channels in cystic fibrosis. From the patch clamp data it is difficult to argue that the sodium channel effects are a result of aberrant chloride transport, yet both alterations in channel properties are a consequence of a single gene defect.

\section{Future therapeutic strategies}

An experiment that many must now be attempting is to transfect various cells with the cDNA for cystic fibrosis transmembrane regulator. This approach may show whether or not the cystic fibrosis transmembrane regulator is the chloride channel. This seems a little unlikely as altered sodium channel characteristics are retained in isolated patches. More probably it will be shown that transfection of cystic fibrosis cells with the cystic fibrosis transmembrane regulator $\mathrm{cDNA}$ will correct the ion channel abnormalities. In the long term transfection of airway epithelium in patients with cDNA in a retrovirus vector may be possible. Insufflation of the appropriate material into the respiratory tract may be easily arranged and considerable improvement might be envisaged even from transfection of only a fraction of the affected cells. Major obstacles need to be overcome before ethical permission is likely to be given, not the least of which is the possibility of switching on cellular oncogenes.

An alternative approach is to correct the transport irregularities with agents active from the apical surface. Nebulisation provides a route of administration that is likely to confine the pharmacological effect to the airways. Amiloride, an epithelial sodium channel blocker, is an obvious candidate and has been tried. ${ }^{31}$ Fourteen volunteer adults with cystic fibrosis took part in a study in which amiloride solution or control vehicle was administered by nebuliser in a double blind crossover study with two 25 week treatment periods. The mean (SEM) loss in forced vital capacity was reduced significantly from $3.4(1 \cdot 1) \mathrm{ml} /$ day with vehicle to $1.4(0.7) \mathrm{ml} /$ day with amiloride. Furthermore, the rheological properties of the secretions returned to virtually normal values during amiloride administration, though bacterial contamination was unmodified. This trial raises the possibility that prophylatic treatment for young patients with cystic fibrosis before acute respiratory symptoms have developed may be worthwhile. Analogues with greater potency or a longer duration-for example, benzamil ${ }^{32}$ might be more useful.

As we have seen, evidence suggests that, at least in airway epithelia, chloride secretion fails in response to secretagogues working via cAMP whereas agents that increase $\mathrm{Ca}_{i}$ are still effective. Simultaneous inhibition of sodium absorption and stimulation of chloride secretion may prove even more effective than the former alone. There is an added incentive to develop this strategy because when amiloride blocks the apical sodium channels in airway epithelia a profound hyperpolarisation of the apical membrane results, exactly what is required to promote chloride exit from the cell provided that apical chloride channels can open. Thus a small increase in chloride conductance may have an amplified effect on chloride secretion in the presence of amiloride. Several ways of increasing chloride conductance may be envisaged, via novel agents that raise $\mathrm{Ca}_{i}$ or development of chloride channel openers working independently of normal regulatory mechanisms. Agents of the former 
type are known (for example, thapsigargin ${ }^{33}$ ) but are only experimental tools. Bradykinin promotes chloride secretion in many types of epithelia ${ }^{34}$ and does not require cAMP for its action. Bradykinin receptors are usually located basolaterally ${ }^{35}$ but in airways they are located apically. ${ }^{36}$ Bradykinin, however, also causes bronchoconstriction, clearly undesirable in cystic fibrosis, but is rapidly metabolised by tissue peptidases. Some thought should be given to developing analogues with appropriate pharmacodynamic and pharmacokinetic properties that may promote chloride secretion in airway epithelium.

In view of the similarity between the cystic fibrosis transmembrane regulator and multiple drug resistance proteins mentioned earlier we may ask whether the cystic fibrosis transmembrane regulator performs a similar function, expelling unwanted endogenous substances from cells that otherwise alter the functioning of other systems, such as the behaviour of sodium and chloride channels. The number of endogenous materials which, in excess, might have this effect is obviously large but the possibility that a tonic inhibitor of the chloride channel exists is supported by the immediate activation of these channels when the patches are removed from cells at $37^{\circ} \mathrm{C} .^{23}$ Moreover, the volume of distribution of many drugs is increased in cystic fibrosis, indicating that they can penetrate spaces from which they are normally excluded. Is this too a manifestation of an altered function of the cystic fibrosis transmembrane regulator? New information about the cystic fibrosis transmembrane regulator may promote questions where there is already a body of clinically relevant information containing important clues. For example, the immunosuppressive drug cyclosporin has been shown to label multiple drug resistance proteins ${ }^{37}$ and possibly the cystic fibrosis transmembrane regulator is also labelled; if it is, is its function altered? This could be studied in patients receiving transplants and cyclosporin to see whether they show any membrane characteristics of cystic fibrosis and whether these disappear as cyclosporin dosage is reduced. Multiple drug resistance proteins are increased in cells, particularly epithelial cells, when they are exposed to natural cytotoxic drugs, such as vinblastine and vincristine. If the cystic fibrosis transmembrane regulator can also be induced, a search for non-toxic inducers may lead to a useful treatment as cystic fibrosis may be a missense mutuation, where activity of the abnormal cystic fibrosis transmembrane regulator is not destroyed but impaired.

The cystic fibrosis transmembrane regulator with phenylalanine deleted at position 508 accounts for only $70 \%$ of mutations. Other haplotypes, accounting for the other $30 \%$ of mutations, are likely to be discovered soon. This information will provide further clues about which structural features of the cystic fibrosis transmembrane regulator are essential for function.

Summary

Details of ion transporting abnormalities in cystic fibrosis airway epithelium are now known. The central hypothesis, that excessive drying of the airway surfaces is a primary event that leads to all the manifestations of the respiratory insufficiency in cystic fibrosis, is not proved. The hypothesis is, however, consistent with the known transporting abnormalities and is strengthened by the modest clinical improvement produced by a strategy designed to correct the transporting abnormalities. The discovery of the cystic fibrosis gene, together with the presumed structure of the protein product, provides a focal point that must eventually connect the functional abnormalities with the genetic defect. The cellular function of the cystic fibrosis transmembrane regulator must now be the major target in research on cystic fibrosis. Strategies for treatment based on known cellular and molecular abnormalities are beginning to emerge but will be undoubtedly more focused once the responsibility of the cystic fibrosis transmembrane regulator is known.

\section{Addendum}

Since this review was completed the prediction made under "Future therapeutic strategies" has been realised. Complementation studies have shown that the introduction of plasmids containing cystic fibrosis transmembrane regulator cDNA into cultured cystic fibrosis cells does indeed restore a chloride conductance response to cAMP. ${ }^{38} 39$ Additionally, it now appears that the cystic fibrosis transmembrane regulator fails to be glycosylated in cystic fibrosis cells, being retained in the golgi and not transferred to the cell membrane. ${ }^{40} \mathrm{~A}$ plasma membrane location of the cystic fibrosis transmembrane regulator is consistent either with an MDR like function or with its being a direct regulator of ion channel activity.

Results obtained in the author's laboratory were from work supported by grants from the Cystic Fibrosis Research Trust.

1 Rommens JM, Iannuzzi MC, Kerem B, et al. Identification of the cystic fibrosis gene: chromosomal walking and jumping. Science 1989;243:1059-65.

2 Riordan JR, Rommens JM, Kerem B, Zielenski J, Lok S, Plavsic N, Chou JL, Drumm ML, Iannuzzi MC, et al. Identification of the cystic fibrosis gene: cloning and characterisation of the complementary DNA. Science 1989;245:1066-72.

3 Kerem B, Rommens JM, Buchanan JA, et al. Identification of the cystic fibrosis gene: genetic analysis. Science 1989;245:1073-80.

4 Bradley G, Juranko PF, Ling V. Mechanism of multidrug resistance. Biochim Biophys Acta 1988;948:87-128.

5 Kilburn KH. A hypothesis for pulmonary clearance and its implications. Am Rev Respir Dis 1968;98:449-63.

6 Cuthbert AW, Fanelli GM. Effects of some pyrazine carboxamides on sodium transport in frog skin. Br J Pharmacol 1978;63:139-49.

7 Olver RE, Ramsden CA, Strang LB, Walters DV. The role of amiloride-blockable sodium transport in adrenaline induced lung liquid absorption in the foetal lamb. $J$ Physiol 1986;376:321-40.

8 Knowles M, Gatzy J, Boucher R. Increased bioelectric potential difference across respiratory epithelia in cystic potential difference across respiratory epithe

9 Knowles M, Gatzy J, Boucher R. Relative ion permability of normal and cystic fibrosis nasal epithelia. J Clin Invest 1983;71:1410-7.

10 Yankaskas JR, Cotton CU, Knowles MR, Gatzy JT, Boucher RC. Culture of human nasal epithelial cells on collagen matrix supports. Am Rev Respir Dis 1985;132:1281-7.

11 Knowles MR, Stutts MJ, Spock A, Fischer N, Gatzy JT, Boucher RC. Abnormal ion permeation through cystic 
fibrosis regulatory epithelium. Science 1983;221:1067-70.

12 Knowles MR, Stutts MJ, Yankaskas JR, Gatzy JT, Boucher RC. Abnormal respiratory epithelial ion transport in cystic fibrosis. Clin Chest Med 1986;7:285-97.

13 Cotton CU, Stutts MJ, Knowles MR, Gatzy JT, Boucher RC. Abnormal apical cell membrane in cystic fibrosis respiratory epithelium. An in vitro electrophysiological analysis. J Clin Invest 1987;79:80-5.

14 Widdicombe JH, Welsh MJ, Finkbeiner WE. Cystic fibrosis decreases the apical membrane chloride permeability of monolayers cultured from cells of tracheal epithelium. Proc Natl Acad Sci 1985;82:6167-71.

15 Stutts MJ, Cotton CU, Yankaskas JR, et al. Chloride uptake into cultured airway epithelial cells from cystic fibrosis patients and normal individuals. Proc Natl Acad Sci 1985;82:6677-81.

16 Boucher RC, Stutts MJ, Knowles MR, Cantley L, Gatzy $\mathrm{JT}$. $\mathrm{Na}^{+}$transport in cystic fibrosis respiratory epithelia. Abnormal basal rate and response to adenylate cyclase activation. J Clin Invest 1986;78:1245-52.

17 Widdicombe JH. Cystic fibrosis and $\beta$-adrenergic response of airway epithelial cell cultures. Am J Physiol 1986;251:R818-22.

18 Barthelson R, Widdicome J. Cuyclic adenosine monophosphate dependent kinase in cystic fibrosis tracheal epithelium. J Clin Invest 1987;80:179-802.

19 Boucher RC, Cheng EHC, Paradiso AM, Stutts MJ, Knowles MR, Earp HS. Chloride secretory response in cystic fibrosis human airway epithelia. Preservation of calcium but not protein kinase $C$ and $A$ dependent mechanisms. J Clin Invest 1989;84:1424-31.

20 Cheng PW, Boat TF, Cranfill K, Yankaskas JR, Boucher RC. Increased sulphation of glycoconjugates by cultured nasal epithelial cells from patients with cystic fibrosis. J Clin epithelial cells from
Invest 1989;84:68-72.

21 Welsh MJ, Liedtke CM. Chloride and potassium channels in cystic fibrosis airway epithelia. Nature 1986;322:467-70.

22 Frizell RA, Rechkemmer G, Shoemaker RL. Altered regulation of airway epithelial cell chloride channels in cystic fibrosis. Science 1986;233:558-60.

23 Kunzelmann $\mathrm{K}$, Pavenstadt $\mathrm{H}$, Greger R. Properties and regulation of chloride channels in cystic fibrosis and normal airway cells. Pflug Arch 1989;415:172-82.

$24 \mathrm{Li} \mathrm{M}$, McCann JD, Liedtke CM, Nairn AC, Greengard P, Welsh MJ. Cyclic AMP-dependent protein kinase opens chloride channels in normal but not cystic fibrosis airway epithelium. Nature 1988;331:358-60.

25 Schoumacher RA, Shoemaker RL, Halm DR, Tallant EA, Wallace RW, Frizzell $\cdot R A$. Phosphorylation fails to activate chloride channels from cystic fibrosis airway cells. Nature 1987;330:752-4.

26 Jetten AM, Yankaskas JR, Stutts MJ, Willumsen NJ,
Boucher RC. Persistence of abnormal chloride conductance regulation in transformed cystic fibrosis epithelia Science 1989;244:1472-5.

27 Valdivia HH, Dubinsky WP, Coronado R. Reconstitution and phosphorylation of chloride channels from airway epithelial membranes. Science 1988;242:1441-4.

28 Hwang T-C, Lu L, Zeitlin PL, Gruenert DC, Huganir R, Guggino WB. $\mathrm{Cl}^{\prime}$ channels in CF: lack of activation by protein kinase $C$ and cAMP-dependent protein kinase. Science 1989;244:1351-3.

29 Disser J, Fromter E. Properties of $\mathrm{Na}^{+}$channels in respiratory epithelium from $\mathrm{CF}$ and non-CF patients [abstract]. Pediatr Pulmonol 1989;suppl:115.

30 Cuthbert AW, Brayden DJ, Dunne A, Smyth RL, Wallwork $\mathrm{J}$. Altered sensitivity to amiloride in cystic fibrosis. Observations using cultured sweat glands. $\mathrm{Br} \mathrm{J} \mathrm{Clin}$ Pharmacol 1990;29:227-34.

31 Knowles MR, Church NL, Waltner WE, et al. A pilot study of aerosolised amiloride for the treatment of cystic fibrosis lung disease. $N$ Engl $J$ Med (in press).

32 Aceves J, Cuthbert AW. Uptake of ${ }^{3} \mathrm{H}$-benzamil at different sodium concentrations. Inferences regarding the regulation of sodium permeability. J Physiol 1979;295:491-504.

33 Brayden DJ, Hanley MR, Thastrup O, Cuthbert AW. Thapsigargin, a new calcium-dependent epithelial anion secretagogue. Br J Pharmacol 1989;98:809-16.

34 Cuthbert AW, Margolius HS. Kinins stimulate net chloride secretion by rat colon. Br J Pharmacol 1982;75:587-98.

35 Cuthbert AW, MacVinish LJ. Diversity of kinin effects on transporting epithelia. In: Kinns V. Part A. Abe K, Moriya H, Fujii S, eds. New York: Plenum, 1989:103-11.

36 Leikauf GD, Ueki IF, Nadel JA, Widdicombe JH. Bradykinin stimulates chloride secretion and prostaglandin $\mathrm{E}_{2}$ release by canine tracheal epithelium. Am J Physiol 1985;248:F48-55.

37 Foxwell BMJ, MacKie A, Ling V, Ryffel B. Identification of the multidrug resistance-related P-glycoprotein as a cyclosporine binding protein. Mol Pharmacol 1989;36: 543-6.

38 Gregory RJ, Cheng SH, Rich DP, Marshall J, Paul S, Henirk $\mathrm{K}$, et al. Expression and characterization of the cystic fibrosis transmembrane conductance regulator. Nature 1990;347:382-6.

39 Rich DP, Anderson MP, Gregory RJ, Cheng SH, Paul S Jefferson DM,et al. Expression of cysticfibrosis transmembrane conductance regulator corrects defective chloride channel regulation in cystic fibrosis airway epithelial cells. Nature 1990;347:358-63.

40 Cheng SH, Gregory RJ, Marshall J, Paul S, Souza D, White GA, et al. Defective intracellular transport and processing of CFTR is the molecular basis of most cystic fibrosis. Cell 1990;63:827-34. 